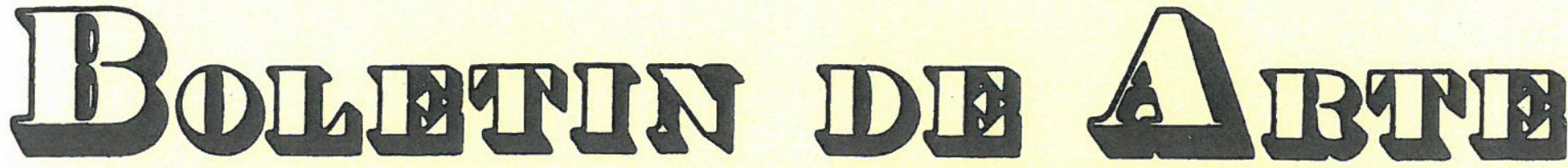

Núm. 20

1999

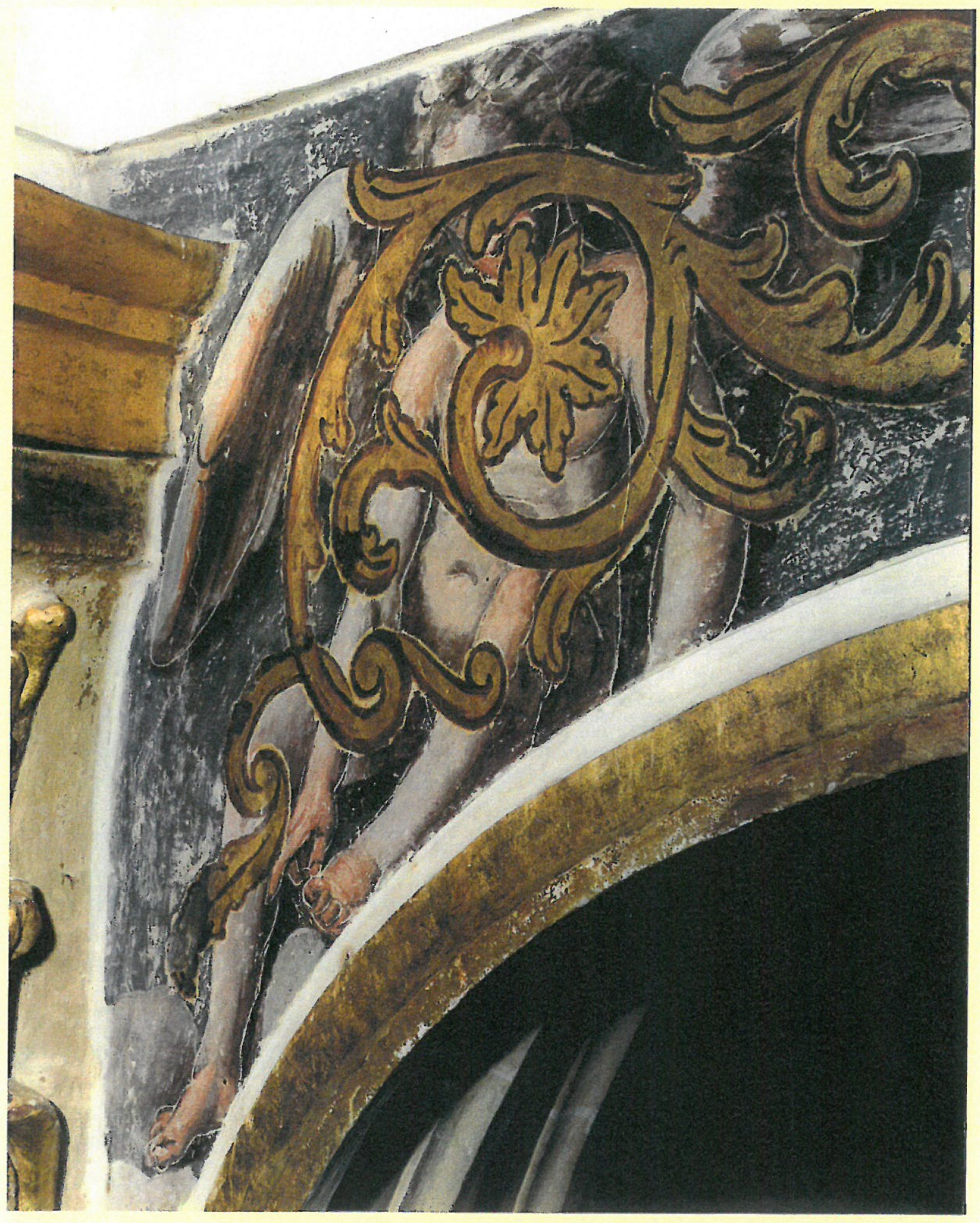

UNIVERSIDAD DE MALAGA

DEPARTAMENTO DE HISTORIA DEL ARTE 
TRANSFORMACIONES URBANÍSTICAS Y PINTURA MURAL EN LA CALLE COBERTIZO DEL CONDE DE MÁLAGA. SU RELACIÓN CON LA CASA-PALACIO DE LOS CONDES DE PUERTOLLANO Y DUQUES DEL ARCO (SIGLOS XV-XIX), por José Angel Palomares Samper

LA DECORACIÓN DE LOS ESPACIOS COMUNES DE LAS VIVIENDAS PLURIFAMILIARES BURGUESAS: PORTALES Y ESCALERAS EN LA MÁLAGA DEL SIGLO XIX, por Francisco García Gómez

EL ESTUCO ESGRAFIADO. COLORES Y FORMAS EN LA ARQUITECTURA MELILLENSE DE LA PRIMERA MITAD DEL SIGLO XX, por Antonio Bravo Nieto

\section{VARIA}

30 AÑOS DE MONUMENTALIDAD GAUDINIANA, Juan Bassegoda Nonell

"SAN ANTONIO DE PADUA", UNA OBRA INÉDITA DE ANTONIO MOHEDANO DE LA GUTIERRA EN EL CONVENTO DE LOS CAPUCHINOS DE ANTEQUERA, por Carmen Herrera Raquejo

EL INVENTARIO DE LOS BIENES DE DOÑA MARIA LUISA DE TOLEDO, HIJA DE LOS MARQUESES DE MANCERA (1707), por José Luis Barrio Moya

"CANONS 22" PARA EL PASEO MARITIMO DE ZARAUTZ, por Elena Asins

EL CATÁLOGO DE ACTUACIONES EN EL CENTRO HISTÓRICO DE MÁlAGA, por Luis Alfonso Martín Delgado

LA CIUDAD VIEJA: APUNTES PARA UNA MIRADA DESCONCERTADA, por Eduardo Asenjo Rubio

\section{CRÍTICA DE EXPOSICIONES}

LA MATERIALIZACION DE LOS SUEÑOS Y SU INTERVENCION EN EL ESPACIO, por Sonia Ríos Moyano 


\title{
EL ESTUCO ESGRAFIADO. COLORES Y FORMAS EN LA ARQUITECTURA MELILLENSE DE LA PRIMERA MITAD DEL SIGLO XX*
}

\section{Antonio Bravo Nieto}

\begin{abstract}
Las artes del estuco y del esgrafiado fueron de las principales técnicas artesanales utilizadas en la arquitectura melillense de la primera mitad del siglo XX. Desde los propios orígenes de la arquitectura modernista se emplearon estucos planchados al fuego y esgrafiados, en fachadas y exteriores, ofreciendo a la obra un acabado de un rico cromatismo que se iría prolongando en los edificios art déco de los años treinta, y en la arquitectura esgrafiada de los cuarenta, donde se fundirán los modelos aerodinámicos con los expresionistas en una envoltura colorista de motivos geométricos y florales de gran belleza.
\end{abstract}

\section{INTRODUCCIÓN}

Hasta el momento, los estudios sobre la arquitectura de Melilla se han centrado básicamente en la clarificación biográfica de sus principales autores y en el análisis de los estilos modernista y art déco ${ }^{1}$, de sus detalles figurativos florales y antropomorfos o de los múltiples elementos ornamentales que caracterizan a una ciudad de fuerte personalidad estilística. Sin embargo, no se ha prestado excesiva atención a algunas de sus artesanías, en concreto a la riqueza de sus estucos y esgrafiados, que son muy significativos tanto en la definición de interiores como en las fachadas ${ }^{2}$.

En este sentido, hay que resaltar la importancia que las diferentes artesanías tuvieron en la caracterización de la arquitectura melillense de la primera mitad del siglo XX. Esta realidad eleva las técnicas de la cal, como las ha definido Ignacio Gárate $^{3}$, a un plano de absoluta prioridad en cualquier análisis que se deba realizar

\footnotetext{
* Este trabajo forma parte de las investigaciones llevadas a cabo en el Proyecto de Investigación I+D PB95-0477 de la DGICYT "La arquitectura pintada en Málaga y Melilla. Siglos XV-XX"

'Ver sobre todo los trabajos de GALLEGO ARANDA, Salvador: Enrique Nieto en Melilla: La ciudad proyectada. Melilla-Granada, UNED y Universidad, 1996; 579 págs. y de BRAVO NIETO, Antonio: La construcción de una ciudad europea en el contexto norteafricano. Arquitectos e ingenieros en la Melilla contemporánea. Melilla-Málaga: Ciudad Autónoma-Universidad, 1996; 700 págs. y La ciudad de Melilla y sus autores. Diccionario biográfico de arquitectos e ingenieros, finales del siglo XIX y primera mitad del XX. Melilla: Ciudad Autónoma, 1997; 211 págs.

2 CASADEVALL I SERRA, Joan (dir.) y otros: Plan del Color de Melilla. I Carta de Colores, II Documentación Técnica, octubre de 1995, Emvismesa Procolor, Akzo Nobel Coatings S.A. Gabinete del Color.

${ }^{3}$ GARATE ROJAS, Ignacio: Artes de la Cal. Madrid: ICRBC, 1994; 382 págs.
} 


\section{Antonio Bravo Nieto}

sobre este periodo, enriqueciendo con ello la visión sobre un fenómeno arquitectónico realmente singular.

Sería imposible, en la extensión de este artículo, determinar todos los aspectos y las características del uso de los estucos y de los esgrafiados en la arquitectura melillense. En principio existen múltiples muestras de artesanías interiores cuya trascendencia no vamos a analizar aquí. También vamos a prescindir del estudio de los detalles ornamentales incisos (florales o geométricos) que podemos encontrar en las fachadas de numerosos edificios de la ciudad, sobre todo en la arquitectura modernista popular del segundo y tercer decenio. Señalaremos que la mayor parte de la arquitectura melillense de la primera mitad del siglo, que comprende corrientes formales muy diferentes, utiliza en sus fachadas diferentes técnicas del revoco y estucado. Así podemos encontrar revocos lisos o rugosos, enlucidos finos con despiece de sillares, estucos marmóreos y planchados al fuego, esgrafiados e incluso
superficies veteadas al fresco.

En este punto debemos precisar que centraremos nuestro análisis sobre un conjunto de edificios de estilos muy variados pero cuyo denominador común es el uso de esgrafiados en la ornamentación de fachada. Estos esgrafiados están ejecutados, en su mayor parte, sobre estucos marmóreos y, en bastantes casos, sobre otros que utilizan la técnica del planchado al fuego. Siguiendo estos parámetros hemos seleccionado 62 edificios cuya cronología arranca de 1909 y llega hasta finales de los años cuarenta, sobre los que realizaremos el análisis que presentamos en este
artículo.

\section{EL ESTUCO Y EL ESGRAFIADO COMO DEFINICIÓN DE EXTERIORES.}

Joan Casadevall en su estudio y propuesta sobre el Plan del Color de Melilla ${ }^{4}$, enumeraba las distintas técnicas del revoco y del estuco seguidas en la arquitectura de esta ciudad. Siguiendo a este autor, señalaremos que la ejecución de cualquier estuco pasa por varias fases técnicas. Sobre el muro de mampostería se ejecuta en primer lugar el denominado zarpeado o relleno de las grietas con aglomerante de cal aérea o una pasta compuesta por árido silíceo. En segundo lugar se ejecuta el enfoscado (el "arenatum" de Vitruvio), compuesto por una pasta de árido cuyo espesor alcanza de 6 a 10 milímetros y que también es denominado zajarrado en la profesión del albañil, que es el operario que realiza esta labor.

Un nuevo proceso se inicia con la tercera fase, el revoco (denominado estuco en Cataluña), donde se inicia el trabajo del estucador propiamente dicho. Éste se materializa con la aplicación de una primera capa de mortero de 2 milímetros compuesto por cal o arena. En esta fase es donde aparece por primera vez el color,

${ }^{4}$ CASADEVALL I SERRA, Joan: Op. cit. 
El estuco esgrafiado. Colores y formas en la arquitectura melillense de la primera ...

ya que se solía aplicar a la pasta un pigmento que le confería al revoco una tonalidad determinada. Por su parte, este pigmento estaba formado a partir de minerales y productos inorgánicos (tierras u óxidos) porque los colorantes orgánicos no resultaban estables a la luz y no podían resistir la causticidad de la cal. Posteriormente se acometía la compactación meticulosa de esta capa de acabado.

En la cuarta fase se realizaba el enlucido fino del estuco, un nuevo mortero de cal aérea de 1 milímetro, compuesto de polvo de mármol fino y pigmentos que normalmente podían alisarse y bruñirse en frío, o también en caliente si se ejecutaba la técnica del planchado al fuego, lo que representaba un acabado casi pictórico de la superficie.

Este último proceso se iniciaba aplicando al estuco una lechada de cal jabonosa teñida de color, sobre la que se aplicaba una plancha metálica muy caliente que conseguía compactar la superficie y proporcionaba la característica imagen del mármol pulimentado y satinado ${ }^{5}$.

La utilización en el acabado de fachada de estucos planchados al fuego refleja un cambio a la hora de concebir la decoración de los edificios, el rechazo a los paramentos texturados, así como el gusto por las superficies de un cromatismo más intenso que admitía diferentes veladuras de acabado. Rojos ocres (hematites), sienas y amarillos, o algunos verdes y azules, son los colores habituales que se emplean en este tipo de estucos.

Por su parte, el esgrafiado es una técnica de influencia italiana que permitía acabados de cierta riqueza y elegancia. En Cataluña esta técnica tuvo un gran auge a partir del siglo XVII y, posteriormente, los esgrafiados fueron utilizados ampliamente en la arquitectura modernista y art déco. En su ejecución se partía del soporte aún fresco del revoco enlucido, superficie sobre la que se trasladaba el dibujo que se deseaba conseguir mediante estarcido o bien utilizando plantillas de zinc en negativo que generaban motivos seriados. Finalmente el dibujo se recortaba sobre el mortero fresco y aparecía el dibujo.

Las técnicas tenían variaciones según los lugares donde se ejecutaban. En Melilla, Antonio Olivares del Rey, que trabajó en el taller que dirigía Joaquín Aznar, nos ha explicado como en algunos casos de los años cuarenta los estucos eran ejecutados con una sola capa de revoco pigmentado y cómo los esgrafiados se conseguían aplicando sobre el revoco, aún fresco, planchas metálicas con el dibujo en negativo que cortaba los contornos ${ }^{6}$, hecho que permitía reproducir los motivos al mismo tiempo que se planchaba la superficie estucada.

\footnotetext{
5 GÁRATE, Ignacio: Op. cit., págs. 208-209 explica esta técnica señalando como se genera un cristal de $\mathrm{CO} 3 \mathrm{Ca}$ que le proporciona al estuco el aspecto satinado.

${ }^{6}$ Estas planchas utilizadas en los estucos de Melilla serían de acero inoxidable y puño de madera, de unos 20 centímetros de largo por 3-4 centímetros de ancho en las planchas lisas, y de 20 centímetros de largo por 6 centímetros de ancho en las planchas que presentaban dibujos.
} 


\section{Antonio Bravo Nieto}

\section{LOS ESGRAFIADOS EN LA ARQUITECTURA MODERNISTA.}

La técnica del estuco planchado al fuego abunda en Melilla en los interiores de edificios modernistas, sobre todo en portales y zócalos, pero también es cierto que no es una técnica que se prodigue en el acabado de exteriores.

La decoración volumétrica y en relieve que se adueñó de las fachadas, formada por elementos florales y antropomorfos, dejaba poco espacio al esgrafiado o a los estucos, porque en estos casos era necesario una fachada lisa que parecía oponerse al ideal decorativo modernista o ecléctico. Es cierto que son muy abundantes los estucos simulando despiece de sillares o incluso cenefas, pero siempre se manifiestan como una fórmula de complemento de la decoración volumétrica realizada en piedra artificial, por lo que tienden a mostrarse como un elemento secundario.

Sin embargo, sí conocemos muchos edificios modernistas en los que se utilizó la técnica de la decoración incisa, donde el dibujo se consigue trasladando la forma al revoco mediante un punzón, por lo que éste asume una forma lineal característica y no requiere los mismos trabajos preparatorios que el esgrafiado. Suelen aparecer estos elementos ornamentales incisos en sobreventana, sustituyendo a la decoración en yeso o piedra artificial.

Se trata de una decoración característica de la arquitectura popular, al tratarse de una técnica ciertamente barata, que podía sustituir a la omnipresente decoración en relieve. Así ocurre en un edificio de dos plantas en la calle Castelar $n^{\circ} 7$, que presenta tres sobreventanas con detalles incisos, aunque conocemos muchos ejemplos en viviendas de una sola planta.

Otros edificios que presentaban estas características eran de más envergadura, y muchos de ellos podemos catalogarlos claramente dentro de la corriente modernista que a partir de 1909 prende en el ensanche de Melilla, como algunos ejemplos de la calle General Prim $n^{\circ} 17$, otro en la calle Sidi Abdelkader $n^{\circ}$ 8, o en General Prim $n^{\circ}$ 14. Esta técnica también persiste en la arquitectura melillense durante los años veinte, caso del Colegio Hispanoisraelita en la avenida de la Duquesa de la Victoria.

Esta decoración incisa podía oscilar entre dibujos de gran calidad que denotan un diseño cuidado y otros más sencillos que evidencian su carácter popular. Entre los primeros destacaremos la decoración de un edificio de la calle Lope de Vega $n^{\circ}$ 7, donde encontramos unos detalles arabescos vegetales y florales sobre los vanos, que casi llegan por su técnica a emular a algunos esgrafiados. Éstos, presentan un claro aire art nouveau, con un dibujo sobre un fondo de fachada en revoco que simula
sillares. (Fig. 1)

En éste y en otros casos la decoración, sin llegar al esgrafiado propiamente dicho, sí refleja ya una evolución o al menos un mayor trabajo en el diseño sobre el estuco. Ya aparecen dos planos claramente diferenciados, con el dibujo en positivo y no en negativo como en la decoración incisa. 
Señalaremos algunos ejemplos sencillos, como un edificio en la calle García Cabrelles $n^{\circ} 9$, que presenta unos rameados vegetales de sobreventana muy simples, al igual que encontramos en los colegios de Batería Jota realizados por el ingeniero Jorge Palanca y Martínez Fortún entre 1922 y 1923. Un modelo más cuidado es el de la calle Lope de Vega $n^{\circ} 10$, donde destaca un esgrafiado con ondulante juego floral que presenta las características modulaciones del art nouveau (Figura 2).

Otros edificios muestran diseños diferentes, situando las superficies esgrafiadas en zonas distintas, como cenefas o paños. Así, en la calle Gran Capitán $n^{\circ} 21^{7}$, el ingeniero Droctoveo Castañón realiza un edificio donde los esgrafiados aparecen en una cenefa corrida sobre la cornisa y otra en la línea de imposta. El dibujo forma detalles de grecas repetitivas en una fachada muy determinada por los contrastes de color entre los estucos y los detalles de barro y ladrillo visto, dentro de un contexto totalmente ecléctico. Formando parte del mismo proyecto, pero con fachada a la calle García Cabrelles $n^{\circ} 24$, aparece un edificio de floralismos más modernistas que tiene su correspondiente ornamentación en relieve, pero que presenta un fondo de flores de lis esgrafiadas (idénticas a las del edificio anterior) en todo el estucado de fachada.

Muy cerca de éstos, en la calle García Cabrelles n 12 , el ingeniero Emilio Alzugaray Goicoechea ${ }^{8}$ proyecta en 1913 un edificio de tres plantas, situando un frente de esgrafiados vegetales en uno de los paños de la fachada. Éste caso es uno de los pocos ejemplos donde el esgrafiado asume un papel de cierta relevancia en la ornamentación de fachada de un edificio modernista ${ }^{9}$.

Todas estas viviendas plurifamiliares de la zona centro y con destino a alquiler, también tenían su paralelo en otras casas construidas en los barrios obreros de la ciudad. En el barrio del Real destacan varios ejemplos con algunos esgrafiados, de entre los que sobresalen por su sencillez y elegancia unos esgrafiados de líneas vegetales esquemáticas sobre los vanos en el n 19 de la calle Zamora, aunque también existen otros en las calles Salamanca $n^{\circ} 7$ o en Aragón $n^{\circ} 9$.

Hay que señalar que las técnicas esgrafiadas, incisas o en huecorrelieve, de la arquitectura melillense de los años diez y veinte fueron realmente minoritarias. Sin embargo, existen algunos edificios (en concreto señalaremos los tres más significativos) donde los esgrafiados asumen un mayor protagonismo, englobando no una parte sino la totalidad de la envoltura estucada del edificio.

\footnotetext{
${ }^{7}$ Archivo de la Comandancia de Obras de Melilla (ACIML). Exp. Jorge Solanilla, del ingeniero Droctoveo Castañón Reguera, proyecto de 30 de junio de 1910.

${ }^{8}$ AMML. JA. Exp. Mariné Prast. Proyecto del ingeniero Emilio Alzugaray para José Mariné Prast en la calle García Cabrelles n ${ }^{\circ} 12$, de 20 de febereo de 1913.

${ }_{9}^{9}$ Por otra parte, a principios de los años veinte también se empleó la técnica del huecorrelieve, caso de unas guirnaldas con fondo dorado en los bajos de un edificio modernista que realiza el ingeniero Enrique Álvarez en 1921, en la calle Castelar n 48. AMML. JA. Exp. León Orden, José. Proyecto del ingeniero Enrique Álvarez para José León Orden, 1919-1920. La obra se finalizó en agosto de 1921 . Actualmente demolido.
} 


\section{Antonio Bravo Nieto}

En primer lugar nos referiremos a un edificio de tres plantas situado en la plaza Comandante Benítez, esquina a García Cabrelles y Gran Capitán, con esgrafiados en la fachada a la citada plaza a partir de flores rameadas de composición repetitiva y dispuestas geométricamente por todo el paramento. En la calle Castelar $\mathrm{n}^{\circ} 71$ también nos encontramos con un edificio de tres plantas que presenta todo el paramento estucado y esgrafiado, repitiendo los rameados anteriores. La ruina actual del edificio, con las correspondientes pérdidas del revoco, nos permite apreciar los colores originales de los esgrafiados que eran de tonos rojizos y ocres en la zona de relieve y más claros en el fondo, lo que implica que la verdadera imagen de este edificio apareciera determinada por el color, en concreto por el contraste de tonalidades del esgrafiado. (Figura 3)

En la calle Padre Lerchundi $n^{\circ} 5$ encontramos finalmente el ejemplo más espectacular por su buen estado de conservación. Se trata de un edificio de cuatro plantas que presenta su fachada con un cuerpo saliente cuyo frontal está totalmente esgrafiado. Esta decoración se estructura simétricamente en cuatro pilastras acanaladas que recorren toda la superficie y que crea tres franjas verticales donde se abren tres ventanas y tres paños esgrafiados por planta. Estos esgrafiados presentan detalles vegetales y rameados de formas muy eclécticas, casi de filiación plateresca, en tonalidades rojizas y sienas. (Figura 4 )

\section{LOS ESGRAFIADOS EN LOS AÑOS TREINTA. LAS SOFISTICACIONES DEL MUNDO ART DÉCO.}

Es evidente que las técnicas del estuco y del esgrafiado ya estaban muy presentes en las artesanías que caracterizaron el mundo de la arquitectura melillense que se ha denominado como modernista, pero señalaremos ahora que estas técnicas van a tomar un especial auge a partir de finales de los años veinte. Ya en la década de los treinta se materializa un cambio notable en la arquitectura melillense, pues la anormal persistencia del modernismo tocaba a su fin, hecho que representó el abandono de la decoración de piedra artificial en relieve. Con ello se tendía hacia un concepto más esquematizado de la decoración basado en el uso de placas ornamentadas y también de los esgrafiados, de acuerdo a tendencias formales que nos remontan al art déco y al propio secesionismo vienés.

Esto se observa en Melilla cuando la ornamentación volumétrica en relieves, miradores con columnas, balcones, ménsulas, balaustradas, sobreventanas, remates y cornisas, desaparece en detrimento de otra decoración más plana, caracterizada por el uso de placas en bajorrelieve con motivos geométricos repetitivos y donde el color juega un papel mucho más importante. Hablamos de edificios en los que se ha producido una importante simplificación de lo ornamental, como el proyectado por el arquitecto Francisco Hernanz en la calle Teniente Coronel Avellaneda 
El estuco esgrafiado. Colores y formas en la arquitectura melillense de la primera ...

$\mathrm{n}^{\mathrm{o}} 3^{10}$, con unas placas cuadrangulares bajo los vanos donde mezcla el hueco con el bajorrelieve, dentro de un diseño claramente art déco. Demostrando que las cuestiones ornamentales dependían más de los talleres artesanales que del propio diseño de los arquitectos, encontramos los mismos motivos ornamentales en un edificio de otro técnico, Enrique Nieto Nieto, esta vez en la calle Padre Lerchundi $n^{\circ} 6^{11}$.

En otros casos se mezclaban y combinaban elementos como los estucos, las placas en relieve, un uso muy comedido de los esgrafiados y paramentos revocados que imitaban ladrillo visto, como podemos observar en una serie de edificios muy similares, caso del construido en la calle Antonio Falcón $n^{0} 7^{12}$, en García Cabrelles $n^{\circ} 6$ o en Capitán Cossío $n^{\circ} 10$, todos ellos en tonos sienas, y en los que podemos apreciar que el esgrafiado todavía no había tomado la relevancia que conseguiría posteriormente.

A partir de estos casos podemos constatar como la utilización de los estucos esgrafiados en exteriores fue un proceso lento que pasaría previamente por su aplicación en lugares concretos en los que cumplía la función de sustituir una decoración más volumétrica, situada casi siempre en los enmarques de vanos. Estos esgrafiados desplegaban finalmente motivos vegetales esquematizados y sometidos a un proceso permanente de estilización y geometrización.

Así lo vemos en algunos edificios construidos por Enrique Nieto en 1934 como el situado en la calle Explorador Badía ${ }^{\circ} 13^{13}$, con sobreventanas esgrafiadas y paramento almohadillado, dentro de una composición de fachada muy convencional. También es el caso de la calle Pradilla n² 24-26. Menos rígido en la articulación de la planta y en el volumen general resulta una obra en la calle Bueno Espinosa $n^{\circ} 10^{14}$ esquina a Pradilla, realizado por Francisco Hernanz en 1934 con esgrafiados algo más cuidados que presentan formas florales esquemáticas.

Está claro que tanto Enrique Nieto como Francisco Hernanz utilizaron los esgrafiados como una opción estética para finalizar sus edificios, pero en estas obras que hasta ahora mencionamos, el esgrafiado no se ha podido desplegar con libertad y sólo ha sustituido a la decoración tradicional. En otro orden de cosas, señalaremos que los dibujos esgrafiados no aparecen nunca definidos en los planos de fachada de los proyectos, por lo que es difícil saber realmente si su diseño se debe al propio arquitecto o al estucador.

\footnotetext{
${ }^{10}$ AMML. SO. Leg. suelto. Proyecto para José Alemany Esplugas de febrero de 1933. Arquitecto Francisco Hernanz Martínez.

11 AMML. SO. Leg. 290, Proyecto para Bernardo Gil Pina, de 2 de abril de 1935. Arquitecto Enrique Nieto Nieto.

12 Archivo Municipal de Melilla (AMML), Servicio de Obras (SO). Leg. 932. Arquitecto Francisco Hernanz Martínez para Mohammed Abderramán Gessus y Ben Yelum, diciembre de 1934 y abril de 1935.

${ }^{13}$ AMML. SO. Leg. 878. Proyecto de edificio de dos plantas para el Hach Hammu Gaderi, arquitecto Enrique Nieto Nieto, de junio de 1934. En septiembre de 1934 se concede la construcción de una planta más. ${ }_{14}$ AMML. SO. Leg. 925. Proyecto del arquitecto Francisco Hernanz Martínez para Jerónimo Callejón, diciembre de 1934.
} 


\section{Antonio Bravo Nieto}

Superando esta fase que acabamos de comentar, el diseño art déco más elegante se materializa en unas serie de obras muy ligadas conscientemente a las estilizaciones y geometrizaciones procedentes de la exposición parisina de 1925 y cuyo principal mentor en Melilla fue Enrique Nieto.

Conocemos cinco obras de la primera mitad de los años treinta donde Nieto desarrolla un lenguaje muy homogéneo que se caracteriza por el uso en fachada de estucos color siena imitando sillería y enmarques de vanos resaltados en tonos anaranjados, verdes o azules, que muestran esgrafiados con motivos vegetales y bandas de azulejo en imposta y peanas de balcones. Estas obras de Nieto muestran un cuidado diseño de volúmenes y una composición de fachada a medio camíno entre una arquitectura tradicional y otra más moderna que bebe en fuentes art déco.

Así lo encontramos en un edificio entre medianeras proyectado en 1934 en la calle General Aizpuru $n^{\circ} 16^{15}$, cuya fachada presenta una serie de esgrafiados sobre estucos planchados al fuego de color amarillo en la que destacan unos balcones curvos sobre ménsulas de estilizado perfil. Siguiendo estas mismas pautas decorativas encontramos dos edificios muy parecidos, uno en la calle Explorador Badía $n^{\circ} 1$ que presenta los mismos marcos con estucos esgrafiados y balcones curvos, y otro realizado en 1935 en la calle Gerona $n^{\circ} 13$, cuyos esgrafiados eran de color azul ${ }^{16}$.

En la calle Benlliure $n^{\circ} 2$, volvemos a encontrar otra obra de esta serie, mostrando ya un mayor interés compositivo y sobre todo por la determinación que el color verde asume en los esgrafiados sobre estuco planchado al fuego y las bandas cerámicas del mismo color. (Figura 5) Sin embargo el principal edificio de esta serie es sin duda un edificio construido por Enrique Nieto en el barrio del Real, en la calle Vitoria $n^{\circ} 16-18$, con esgrafiados de diseño floral sobre los vanos de los tres miradores cuadrangulares que articulan una fachada, rematada por un contundente cornisamento que se subraya por una banda de cerámica verde. (Figura 6)

Sin embargo, los mestizajes que pueden observarse en la arquitectura melillense de los años treinta donde aparecen esgrafiados, es absoluto y a veces desconcertante. Si es cierto que en este decenio triunfan los modelos esgrafiados, también lo es que aparecen muchas veces formando parte de conjuntos totalmente eclécticos y donde se utilizan elementos propios de periodos anteriores.

En algún caso, el esgrafiado "comparte" fachada con ornamentación modernista de los años veinte, caso de un edificio en la calle General Margallo ${ }^{\circ}$ 10 , con tres plantas estucadas en tonos anaranjados imitando ladrillo visto y enmarques de vanos en relieve, pero donde también se sitúa un mirador cúbico en

\footnotetext{
15 AMML. SO. Leg. 902. Proyecto de Enrique Nieto de fecha 1 de agosto de 1934, finalizándose las
obras en 16 de enero de 1935 .

${ }^{16}$ Lamentablemente la única solución que se lleva a cabo actualmente para conservar estos estucos y los dibujos esgrafiados, debido a su deterioro, es el repintado. La gama de colores que se sigue para ello se mueve siempre en tonos ocres y marrones, con lo cual se pierde el cromatismo original que era mucho
más amplio.
} 
El estuco esgrafiado. Colores y formas en la arquitectura melillense de la primera ...

el centro, con una placa triangular con esgrafiados cuyo diseño forma juegos geométricos. Por vez primera el esgrafiado abandona los lugares convencionales donde solía situarse la decoración modernista para adueñarse de las superficies y fachadas con más libertad.

También conocemos diversas ampliaciones sobre edificios anteriores en los que se conservó la ornamentación modernista en el bajo y se aplicaban los esgrafiados en los pisos superiores, como encontramos en la calle Teruel $n^{\circ} 10$, obra que realiza Francisco Hernanz en $1935^{17}$.

En otras obras de fachadas esgrafiadas llegaron incluso a aplicarse cornisas muy clásicas e incluso cresterías historicistas, que contrastaban con unas superficies que adoptaban estucos planchados al fuego de gran interés, en dibujos geométricos de filiación art déco. En esta línea conocemos dos obras del arquitecto Enrique Nieto, una pequeña vivienda en la calle Teruel $n^{\circ} 12$, también con fachada a la calle Almería ${ }^{18}$, con series de enmarques esgrafiados sobre paramento estucado al fuego en tonos rojizos, pero que presenta una trabajada cornisa basada en una serie de cuerda con nudos de gran contundencia, balaustrada de círculos y crestería historicista que ofrecen una imagen muy tradicional y poco moderna, aunque las geometrizaciones nos remitan al art déco.

El otro ejemplo es una interesante muestra situada en la calle Jardines $n^{\circ} 1^{19}$. Un edificio de 4 plantas aparentemente convencional, con dos miradores de madera que recorren todas las plantas, y crestería goticista en su remate, sin embargo presenta la fachada con estucos al fuego en tonos azules de gran belleza, mientras que los enmarques de vanos aparecen en tonos verdes, hoy muy deteriorados. Los motivos esgrafiados ocupan prácticamente toda la fachada y muestran esquematizaciones, series repetitivas de dibujos lineales y geométricos de filiación art déco. Se trata de una obra que ha transformado cualquier ornamentación figurativa en una envoltura totalmente esgrafiada y cuyo cromatismo azul y verde resultaba una apuesta decidida por el color. No sólo fue Nieto quien realizó experiencias eclécticas como las que hemos visto, sino que un arquitecto mucho más en la vía racionalista como Francisco Hernanz, también diseña algún edificio con concesiones a una arquitectura más tradicional. Así ocurre en la calle Fernández Cuevas nº 15 esquina a Luis de Cappa ${ }^{20}$, en un edificio de tres plantas con bonitos esgrafiados en los marcos de vanos e incisiones en huecorrelieve en los antepechos. Los estucos planchados de tonos

\footnotetext{
17 AMML. SO. Leg. 953. Proyecto para el Sr. Salinas, arquitecto Francisco Hernanz Martínez, de enero
de 1935 . 18 AMML. SO. Leg. 987-s. Proyecto del arquitecto Enrique Nieto Nieto para Diego Moral, de junio de
1935 en la calle Nackens ${ }^{\circ}$ 12.

${ }_{19}$ AMML. SO. Leg. 838, Proyecto del arquitecto Enrique Nieto Nieto en la calle Jardines $n^{\circ}$ 1, de junio de 1933 para Ahmed Ben Taleb Amar, ampliando una casa anterior. ${ }^{20}$ AMML. SO. Leg. 780. Proyecto del arquitecto Francisco Hernanz Martínez para Mariano San Martín
Gimenez, de 7 de diciembre de 1932 .
} 


\section{Antonio Bravo Nieto}

anaranjados en el fondo y azules en los detalles de sobreventanas y en la esquina (lugar donde se realiza una bella placa de estilizaciones esgrafiadas), caracterizan una obra de original cromatismo. (Figura 7-8)

Otro edificio de Francisco Hernanz en la calle García Cabrelles nº 22 esquina a Alférez Sanz ${ }^{21}$, también presenta placas con decoración esgrafiada sobre estucos planchados, de tonos rojizos sobre fondo más claro de filiación art déco, con líneas en zigzag, bandas y rayos. (Figura 9)

Otro grupo de edificios asume una imagen más cúbica y rotunda en sus angulosidades, fruto de la evolución que la propia arquitectura había experimentado ya a mediados de los años treinta. Éstos presentan miradores o cuerpos cúbicos que suelen volar sobre el nivel de la fachada y cuya superficie fue un buen lugar para plasmar la decoración esgrafiada.

Así destacaremos un edificio de dos plantas realizado por Francisco Hernanz en 1933 en la calle Jiménez Benhamu $n^{\circ} 1^{22}$, en el que destacan esgrafiados de sobreventana con dibujos florales geométricos tipo art déco, sobre una fachada cuyo revoco simula despiece de sillares a la martillina. (Figura 10) Señalaremos que estos mismos motivos también fueron utilizados en edificios documentados de Enrique Nieto, por lo que una vez más nos encontramos con talleres artesanales que trabajaban para todos los técnicos, sin que la repetición de modelos pareciera ser un impedimento grave para los arquitectos.

También del mismo estilo contamos con un ejemplo situado en la calle Cándido Lobera $n^{\circ} 23$, donde los estucos planchados al fuego se ejecutaron en color azul con motivos esgrafiados de diseño geométrico.

Otros ejemplos presentan parecidas características: viviendas de dos o tres plantas, con mirador centrado y balcones laterales. Así ocurre en un edificio construido en 1935 por Francisco Hernanz en la calle Juan de Juanes $n^{\circ} 11^{23}$, de dos plantas y tonos sienas, o en otro ejemplo de la calle Padre Lerchundi $n^{\circ} 45^{24}$, de tres plantas y planteamiento similar, utilizando motivos decorativos esgrafiados en la montera de los vanos, con dibujos geométricos de lejanos referentes vegetales.

En otros casos Francisco Hernanz presenta una obra de más interés, en edificios cercanos a la arquitectura expresionista o art déco aerodinámica plenamente europea e internacional, llena de modernidad y del racionalismo atemperado de los años treinta, sobre algunas de las cuales aplica una elegante ornamentación esgrafiada. El caso más significativo es un edificio construido con proyecto de 1934 en la avenida

\footnotetext{
${ }^{21}$ AMML. SO. Leg. 838. Proyecto del arquitecto Francisco Hernanz Martínez para Ahmed Ben Taleb
Amar, de 23 de abril de 1935. 22 AMML. SO. Leg. $450 \mathrm{~s}$. Proyecto del arquitecto Francisco Hernanz Martínez para Francisco Santander,
de 16 de noviembre de 1933 . ${ }^{23}$ AMML. SO. Leg. 1.000. Proyecto del arquitecto Francisco Hernanz Martínez para Antonio Jiménez
en la calle Juan de Juanes, agosto de 1935 . ${ }^{24}$ AMML. SO. Leg. 964 . Proyecto del arquitecto Francisco Hernanz Martínez para María Almena Barranco,
de enero de 1935 en la calle Padre Lerchundi $n^{\circ} 45$.
} 
El estuco esgrafiado. Colores y formas en la arquitectura melillense de la primera ...

de la Democracia $n^{\circ} 14$ (antigua Teniente Coronel Seguí) ${ }^{25}$. De cinco plantas, tiene un mirador central con ventanas cuadrangulares que articula visualmente unos balcones laterales. El paramento de fondo es un estuco que imita el ladrillo visto de tonalidades ocres y marcos esgrafiados sobre los vanos que contrastan con el revoco del mirador y de los balcones que muestran una tonalidad más clara. Por su parte, los bajos presentan series esgrafiadas al fuego con flores y dibujos vegetales muy geometrizados, formando círculos y formas en estrella. (Figura 11)

Relacionado con el ejemplo anterior en su planteamiento aerodinámico, es un edificio de dos plantas situado en la calle General Astilleros $n^{\circ}$ 9-11, con placas esgrafiadas al fuego con detalles geometrizados.

Este acabado del estuco, a partir de placas esgrafiadas que se podían situar en diferentes partes de la fachada, es el que encontramos en una vivienda terminada en 1936 en la calle Pradilla ${ }^{\circ}$ 16, o en dos edificios situados en el barrio del Carmen. Las fachadas de estos últimos se mueven dentro de una composición muy cúbica de carácter racionalista y donde la ornamentación esgrafiada sobre fondo de estuco planchado al fuego nos ofrece interesantes morfologías. Así en la plaza de Gerona $n^{\circ}$ 6-7 (también con fachada calle Tarragona 9) ${ }^{26}$. Enrique Nieto proyecta un edificio con una interesante serie de esgrafiados en tonos ocres en sus dos fachadas: en sobreventanas, cenefas, placas simulando las ménsulas del mirador y placas con geometrizaciones vegetales uniendo verticalmente los vanos. (Figura 12) Por su parte, en la calle Tarragona ${ }^{\circ}{ }^{15}$, también encontramos varios motivos esgrafiados sobre los vanos y un mirador lleno de figuras lineales en tonos anaranjados.

Finalmente, y para cerrar este apartado de la arquitectura esgrafiada melillense de los años treinta, citaremos un edificio en la calle Ejército Español n ${ }^{\circ} 6^{27}$, realizado por Enrique Nieto junto al Cine Monumental, lo que le determina una cierta influencia de esta última obra. Plantea la fachada con un mirador de desarrollo vertical donde utiliza placas esgrafiadas en cenefa dentro de un ambiente general art déco que asume una ornamentación más cuidada.

\section{ENRIQUE NIETO Y LA ARQUITECTURA ESTUCADA DE LOS AÑOS CUARENTA}

Hasta 1936 los arquitectos Francisco Hernanz y Enrique Nieto asumen la dirección de los edificios donde se realizan los estucos esgrafiados, pero desde 1936 será este último quien dirija en solitario la ejecución de los trabajos. Otros arquitectos que trabajaron en Melilla por entonces no utilizaron estas técnicas, como Manuel

\footnotetext{
25 AMML. SO. Leg. 923. Proyecto del arquitecto Francisco Hernanz Martínez de septiembre de 1934. ${ }^{26}$ AMML. SO. Leg. 1.099. Proyecto del arquitecto Enrique Nieto Nieto para Dioscórides Blanco Antón, diciembre 1937.

27 Gallego Aranda, Salvador. Op.cit. p. 359 y lámina nº 23.
} 


\section{Antonio Bravo Nieto}

Latorre Pastor que proclamaba abiertamente su interés por los paramentos encalados y pintados en tonos discretos, aborreciendo del cromatismo propio del mundo art déco, lo que implicaba el rechazo de los estucos. Será por tanto Nieto quien durante el decenio de los cuarenta continúe realizando diferentes trabajos (de los que hemos contabilizado al menos 22 proyectos) y el que clausure esta técnica esgrafiada en la arquitectura melillense.

Diremos que estas obras nos remiten a unos modelos muy depurados que contrastan abiertamente con la diversidad de opciones que hemos constatado en los años treinta. Nieto huye de las angulosidades y volúmenes cuadrangulares que hemos visto se realizaban en el decenio anterior y siempre tiende a redondear sus aristas con acabados curvos, creando unos modelos lejanamente cercanos a ciertas obras expresionistas. Los últimos edificios donde Nieto utiliza volúmenes prismáticos preludian cómo después de la Guerra Civil española este autor buscaba nuevos caminos formales que le llevarían a rechazar un excesivo cubismo 28 .

El primero se proyecta en 1939, en la actual avenida Duquesa de la Victoria $n^{\circ} 24$, donde desarrolla un interesante programa de esgrafiados sobre estucos planchados al fuego de tonalidades anaranjadas, en una fachada compuesta por dos miradores prismáticos laterales que generan fuertes efectos de luz y sombra ${ }^{29}$. (Figura 13)

En concreto, la fachada presenta una serie de esgrafiados sobre un fondo de estuco imitando ladrillo visto, con bandas lineales, dibujos con geometrizaciones, placas bajo los vanos y palmas y flores muy elegantes que rematan los vanos, elementos que luego se repetirían con profusión en otras obras. (Figura 14) Estos mismos modelos decorativos aparecen en otro edificio de dos plantas construido en el barrio del Real, carretera a Huerta $\mathrm{Cabo}^{30}$, con esgrafiados formando palmas, cenefas y detalles geométricos en los bajos.

Enrique Nieto desarrolla durante los años cuarenta un estilo muy personal y poco dado al encasillamiento. En él funde elementos procedentes de su vasta cultura arquitectónica: las enseñanzas del racionalismo, las superficies estucadas del art déco, los esgrafiados, la articulación aerodinámica de las fachadas y un acabado elegante que define una arquitectura siempre ornamentada. Es una época en la que Nieto realiza sobre todo pequeños proyectos en solares de reducidas dimensiones, donde utiliza técnicas de estuco planchado al fuego con esgrafiados, principalmente en tonalidades rojizas o sienas.

\footnotetext{
${ }^{28}$ A pesar de su ejecución en una fecha tan tardía como 1949, Enrique Nieto también realiza una vivienda en la calle Padre Lerchundi 52 donde sigue modelos más afines a los años treinta, con vanos esgrafiados en tonos anaranjados dentro de la tónica art déco que había caracterizado a algunas de sus obras del decenio Gutiérrez, de 25 de. Leg. 18 s. Proyecto del arquitecto Enrique Nieto Nieto para Carmen Fernández Gutiérrez, de 25 de octubre de 1949, calle Padre Lerchundi 52. ${ }^{29}$ AMML. SO. Leg. s y 309. Proyecto del arquitecto Enrique Nieto Nieto para Manuel Sánchez, enero
de 1939 .

30) AMML. SO. Leg. s/n. Proyecto del arquitecto Enrique Nieto Nieto de enero de 1936 para Antonio Pérez
Orellana.
} 
El estuco esgrafiado. Colores y formas en la arquitectura melillense de la primera ...

En el barrio del Carmen encontramos un abundante número de obras, como en la calle Alicante $n^{\circ} 5^{31}$, de dos plantas con fachada a tres calles que presenta vuelo en el primero para ganar superficie construida e interesante acabado a partir de estucos rojizos y esgrafiados de palmas, bandas lineales y placas de granito en el bajo.

En la calle Sagasta $n^{\circ} 2^{32}$, realiza un edificio que destaca por una conseguida articulación de volúmenes con miradores de perfil cuadrangular cuya arista ha sido suavizada y un balcón que cierra la esquina en modulación curva que ya había aprendido mucho de los aerodinamismos racionalistas. La fachada presenta diferentes placas esgrafiadas y cinco enmarques de vanos con vegetales esquematizados. Frente a esta última, en calle Sagasta $n^{\circ} 1^{33}$ también realiza otro proyecto con estucos planchados al fuego y esgrafiados esquemáticos, en tonalidades rojizas sobre fondo claro y finas bandas de azulejo, que se convierte en una brillante herencia de la elegancia art déco y de la composición racionalista. (Figura 15)

Esta misma circunstancia es la que encontramos en Padre Lerchundi $n^{\circ} 18^{34}$, donde los esgrafiados asumían la forma de cenefas de círculos que bordean los vanos, o en la calle Cánovas $n^{\circ} 2$ donde volvemos a encontrar los mismos círculos esgrafiados ${ }^{35}$.

En la Plaza de Gerona esquina a calle Almería $\mathrm{n}^{\circ}$, encontramos una obra de dos plantas, donde Nieto consigue articular los volúmenes con acertada rotundidad $\mathrm{y}$ al mismo tiempo con la elegancia propia de un autor consagrado ${ }^{36}$. Este edificio presentaba unos esgrafiados tanto en cenefas sobre los vanos como en placas, lamentablemente ocultos en la actualidad por repintes. (Figura 16)

Existen dos edificios donde la plasticidad del estuco esgrafiado adquiere un papel especialmente relevante, utilizando una decoración basada en palmas y las complicadas geometrizaciones vegetales y en estrella repetidas hasta conseguir una superficie de verdadera filigrana: en la calle Ibáñez Marín $n^{\circ} 12^{37}$ y en la calle Aragón $\mathrm{n}^{\circ} 19$ (Figura 17) tenemos las mejores muestras de estas obras, ocupando los esgrafiados el protagonismo total de la ornamentación.

Otros muchos trabajos de Nieto asumen los estucos esgrafiados como solución final de acabado de fachada, pero no de una manera tan preeminente. Así destacaremos diferentes proyectos en el barrio del Real, casi siempre de una o dos

\footnotetext{
${ }^{31}$ AMML. SO. Leg. 1.260. Proyecto del arquitecto Enrique Nieto Nieto para Nuria Martínez, enero de
1944 en la calle Teruel $n^{\circ} 24$.

32 AMML. SO. Leg. s. Proyecto del arquitecto Enrique Nieto Nieto para Juan Ruiz Martín, de 22 de octubre de 1945 en la calle Sagasta.

33 AMML. SO. Leg. 1.267. Proyecto del arquitecto Enrique Nieto Nieto de 24 de marzo de 1944 en la calle Murcia $\mathrm{n}^{\circ} 3$.

34 AMML. SO. Leg. 1.306. Proyecto del arquitecto Enrique Nieto Nieto para Ana Rodríguez Castillo de 21 de febrero de 1944.

35 AMML. SO. Leg. 1.253. Proyecto del arquitecto Enrique Nieto Nieto para José Castillo Gualda, octubre de 1943.

${ }^{36}$ AMML. SO. Leg. s/n. Proyecto del arquitecto Enrique Nieto Nieto para Francisco López García, febrero de 1941 en la calle Almería n ${ }^{\circ} 2$.

${ }^{37}$ AMML. SO. Leg. s/n. Proyecto del arquitecto Enrique Nieto en la calle Ibáñez Marín nº 6, en agosto de 1943 para Juan Fernández.
} 


\section{Antonio Bravo Nieto}

plantas, como en la calle Mar Chica $\mathrm{n}^{\circ} 19$ esquina a Zamora ${ }^{38}$, edificio de volumetría plenamente racionalista (actualmente demolido); en la calle Zamora $n^{\circ} 41-43$ (o Doña Marina $\left.\mathrm{n}^{\circ} 5-7\right)^{39}$, con estucos simulando ladrillo visto y esgrafiados de sobreventana; en la calle Mar Chica $n^{\circ} 17$ esquina a Capitán Andino ${ }^{40}$, que presenta originales esgrafiados florales; en la calle Aragón n 16, utilizando marcos esgrafiados en los vanos sobre una estructura de fachada muy similar a la que encontramos en la calle Cándido Lobera $n^{\circ} 27^{41}$, en la que destaca la carpintería art déco, miradores cuadrangulares y balcón central curvo, todos en tonalidades de estuco rojizas. También destacaremos un edificio de las mismas características en la calle Ibáñez Marín $n^{\circ} 24^{42}$.

Pocas veces el estuco esgrafiado asume la responsabilidad de decorar un edificio de envergadura, más propiamente de ensanche, aunque conocemos tres interesantes proyectos donde Nieto consigue culminar su estilo ampliando la escala de esta arquitectura. En el corazón del ensanche melillense, en la calle Sidi Abdelkader $n^{\circ} 9$, realiza la reforma de un edificio clasicista, aumentándole una planta con la reforma total de su fachada, materializando un juego de volúmenes que articula dos miradores cuadrangulares centrados a partir del chaflán. La nueva fachada asume una superficie totalmente estucada en tonos rojizos, que prescinde de cualquier decoración en relieve para desplegar esgrafiados que forman palmas sobre los vanos.

El segundo edificio de estas características está en la calle Querol nº 52 esquina a General Aizpuru $n^{\circ} 15^{43}$, en el que define una interesante envoltura plástica de ejecución muy aerodinámica, con un gran mirador a una de las fachadas y balcones sobre la otra y en el chaflán. En esta obra ensaya un modelo original de esgrafiado vegetal geometrizado que enmarca todos los vanos y parte de los antepechos de balcones. (Figura 18).

Finalmente en la calle Jacinto Ruiz Mendoza nº 39 encontramos un más que destacable edificio de tres plantas donde dos miradores curvos articulan verticalmente el conjunto y generan tres paños de balcones también curvos. La fachada está totalmente estucada al fuego en tonos rojizos llenos de esgrafiados de diseño original y de gran elegancia, con guirnaldas de flores, dibujos geometrizados y colgaduras vegetales que definen un cromatismo muy interesante, actualmente repintado. ( $F i$ gura 19).

\footnotetext{
${ }^{38}$ AMML. SO. Leg. 721. Proyecto del arquitecto Enrique Nieto Nieto para Francisca Quesada Martínez en la calle Mar Chica n 19 , esquina Zamora, febrero de 1940 y noviembre de 1940.

${ }^{39}$ AMML. SO. Leg. 1.327. Proyecto del arquitecto Enrique Nieto Nieto para Josefa Romero Leal, 1939 y 1946.

${ }_{41}^{40}$ El arquitecto Enrique Nieto Nieto dirigió las obras de este edificio entre 1939 y 1946.

41 Edificio en la calle Cándido Lobera $n^{\circ} 27$. En 1945 se realizaba el aumento de planta.

calle Ibañez Marín no 18 (esquina a de calle Ibañez Marín n ${ }^{\circ} 18$ (esquina a Teniente Coronel Avellaneda), mayo de 1946.

entre 1944-1945.
} 
El estuco esgrafiado. Colores y formas en la arquitectura melillense de la primera ...

Terminaremos este trabajo señalando dos edificios que representan el final del periodo, lo que podríamos definir como las últimas obras estucadas de la arquitectura melillense, y no tanto por su cronología sino porque anuncian el cansancio de estas formas. Nos referimos a un edificio en la calle Castelar $n^{\circ} 52^{44}$, que presenta fachada estucada con bandas geométricas, placas de estuco rojo y bandas anaranjadas y que huye totalmente de cualquier decoración figurativa, al excluir los esgrafiados. La otra obra es más interesante al presentar una mezcla de la técnica del estuco esgrafiado con una ornamentación más volumétrica. En la calle Antonio Zea $n^{\circ} 11$ $13^{45}$ Enrique Nieto construye un edificio de dos plantas con cuatro miradores cuadrangulares que cierran tres espacios abalconados. La decoración utiliza placas esgrafiadas vegetales en estuco gris o azulado, pero que también alterna con aplacados en relieve o huecorrelieve. Resulta obvio como en estas dos últimas obras, Nieto asume el agotamiento tanto del estuco como del esgrafiado, y a partir de entonces se materializa la desaparición de cualquier referencia ornamental figurativa en la arquitectura melillense. Desde ese momento su historia constructiva correrá por otros caminos más ligados al movimiento internacional que rompe con cincuenta años de una forma de hacer ciudad, basada en una arquitectura ornamentada y esencialmente dirigida a generar efectos de belleza.

\footnotetext{
${ }^{44} \mathrm{El}$ arquitecto Enrique Nieto Nieto declaraba una instancia catastral que había terminado esta casa el 3 de febrero de 1947. ${ }^{45}$ AMML. SO. Leg. s/n. Proyecto del arquitecto Enrique Nieto en la calle Antonio Zea $n^{\circ} 11$ y Hernando
de Zafra $n^{\circ} 5,30$ mayo de 1947.
} 


\section{Antonio Bravo Nieto}
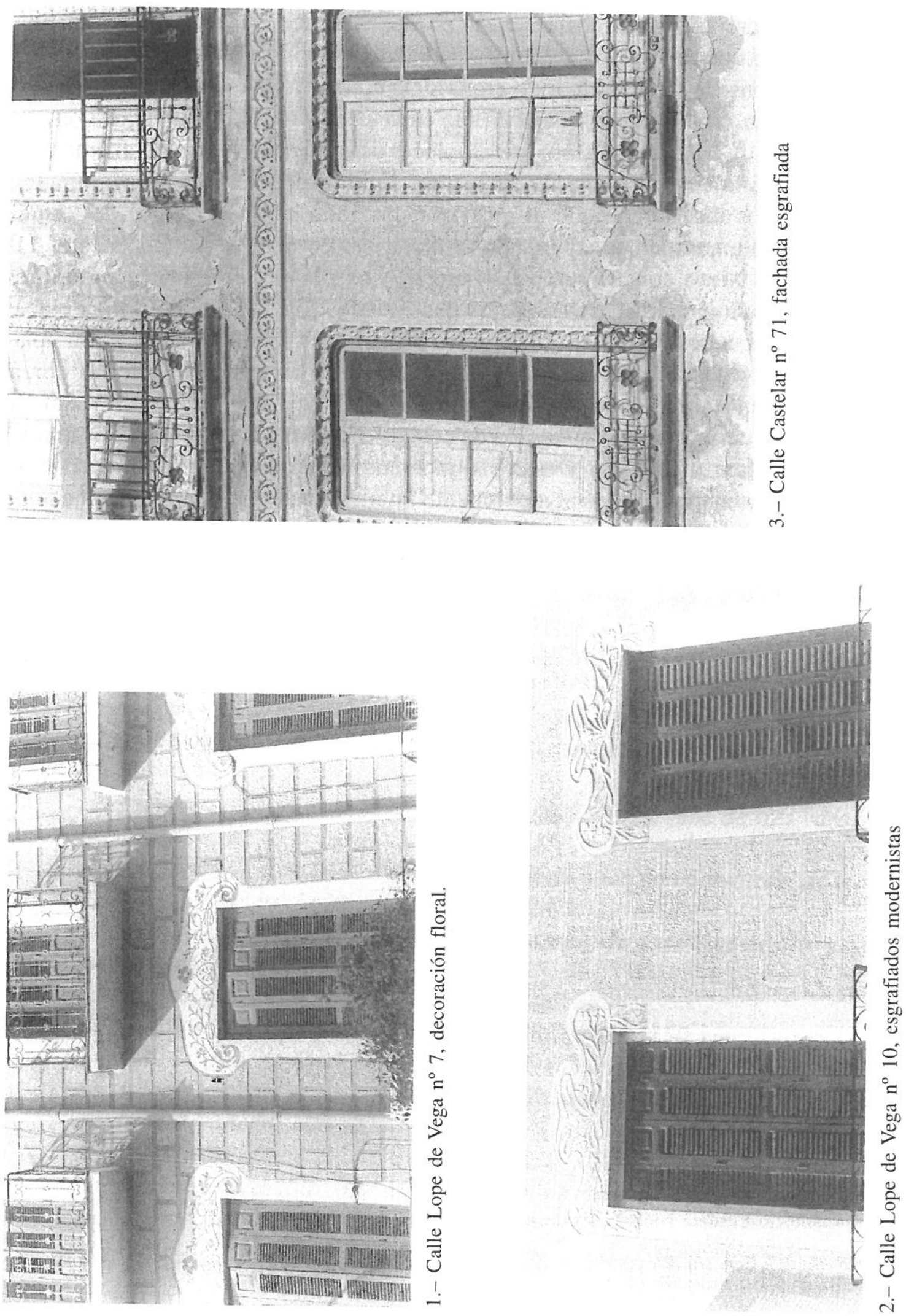
El estuco esgrafiado. Colores y formas en la arquitectura melillense de la primera ...
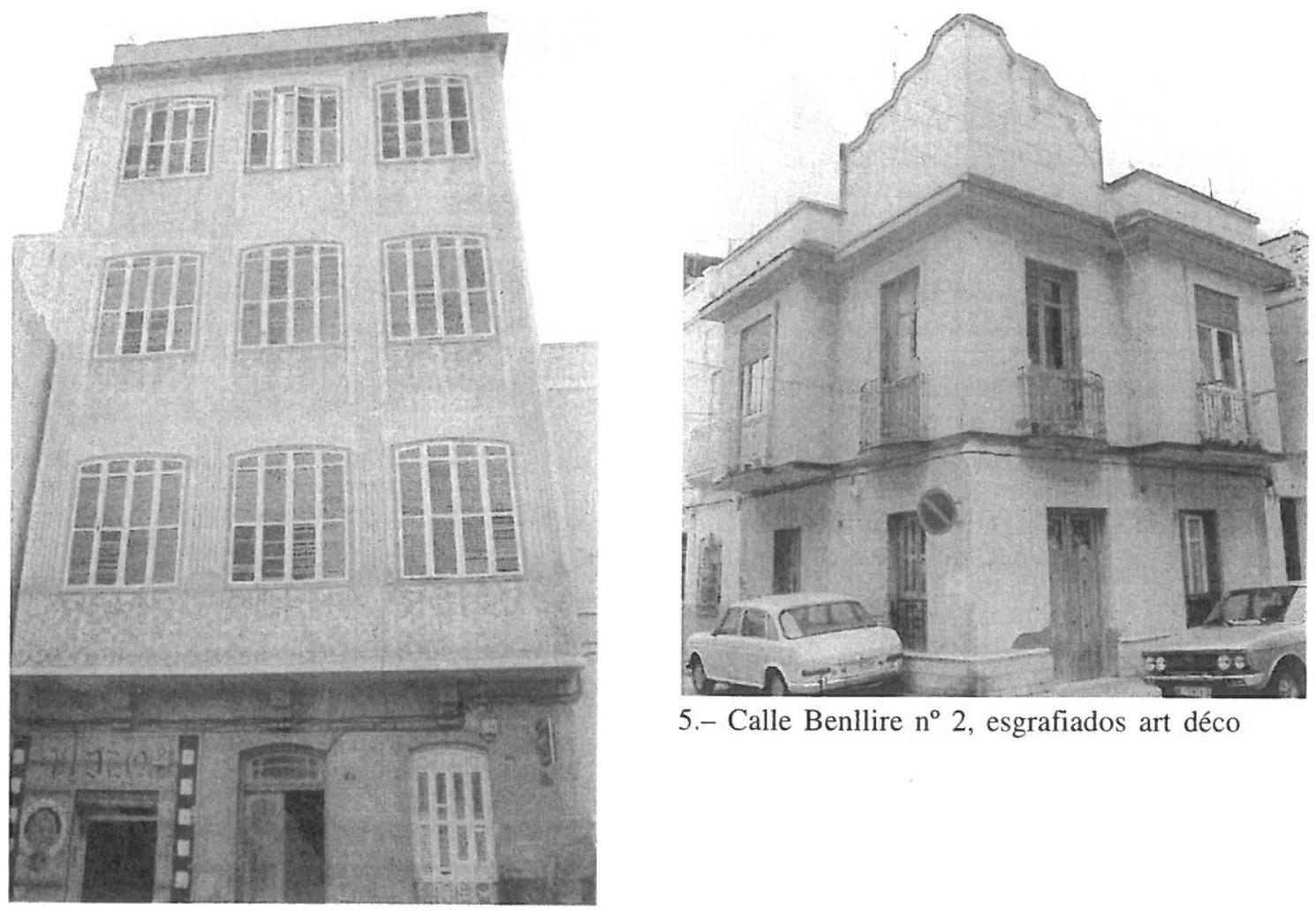

5.- Calle Benllire $n^{\circ} 2$, esgrafiados art déco

4.- Calle Padre Lerchundi $n^{\circ} 5$, fachada esgrafiada

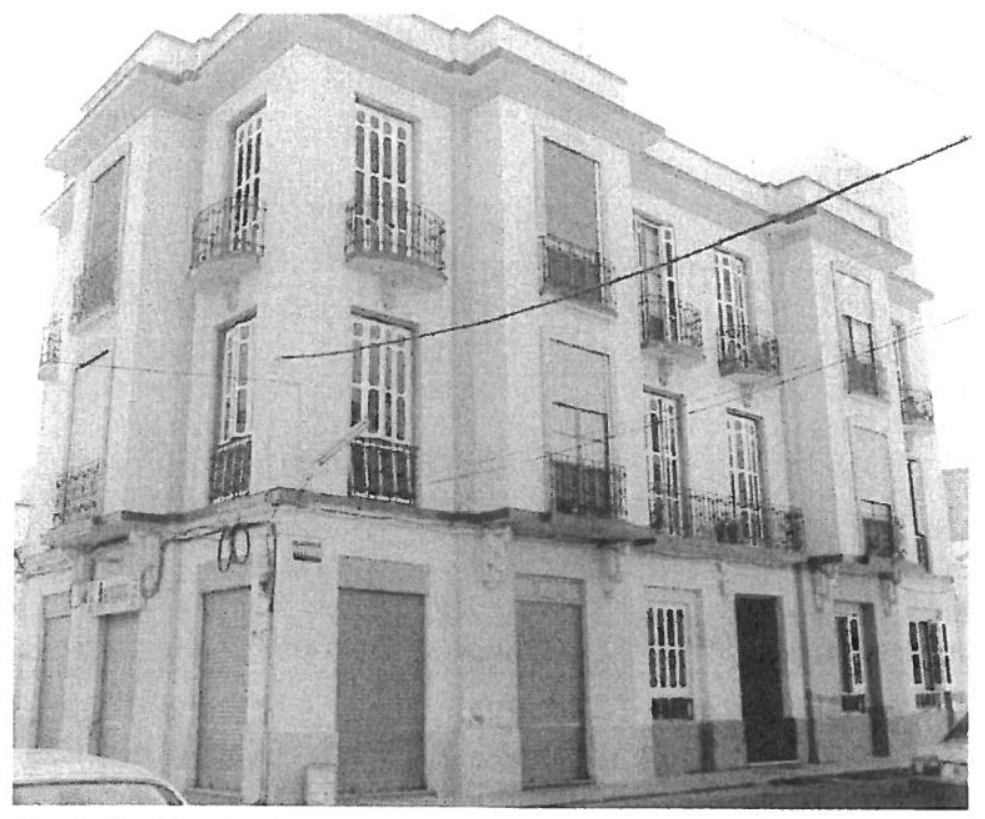

6.- Calle Vitoria $\mathrm{n}^{\circ} 16-18$, arquitecto Enrique Nieto 

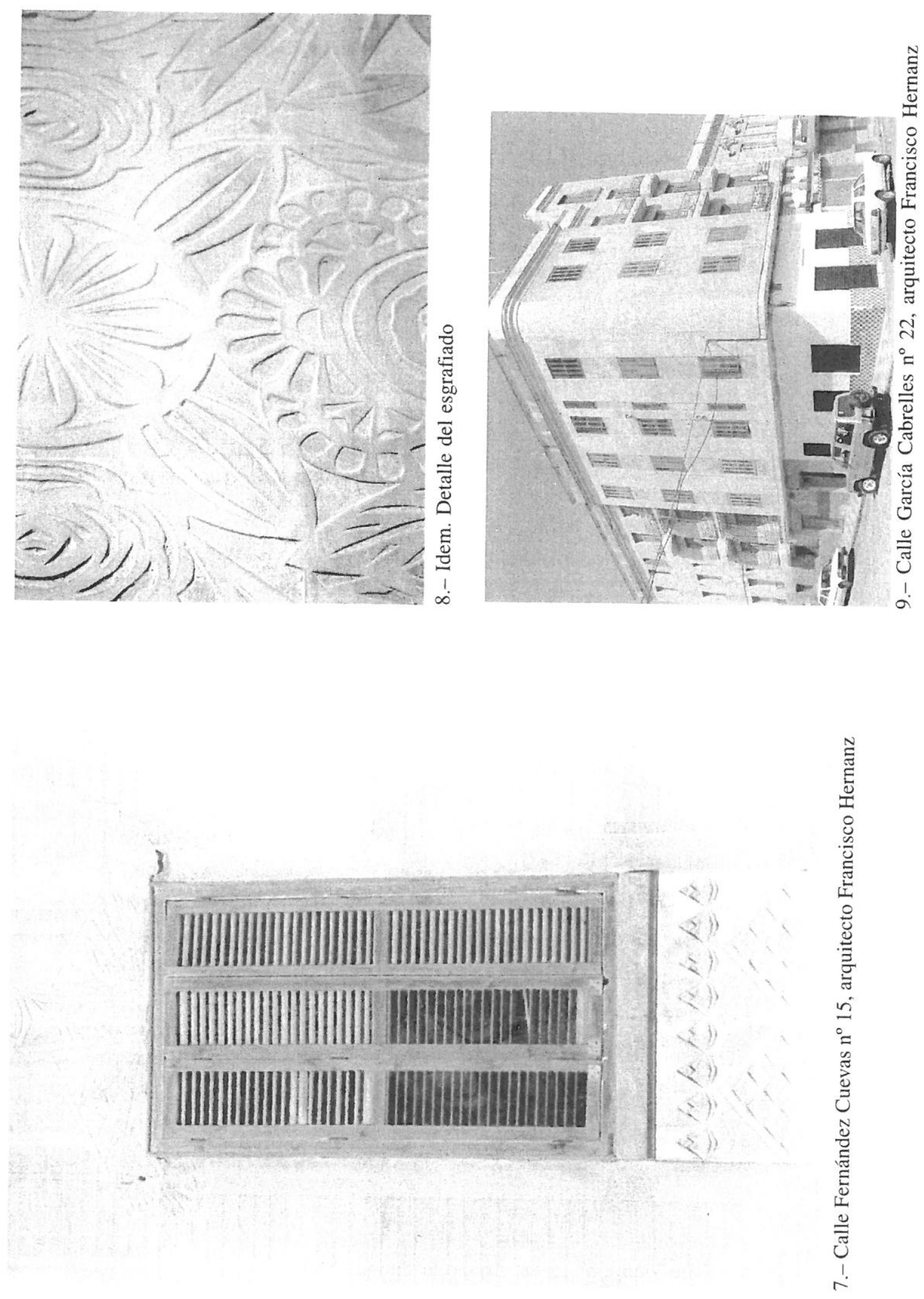
El estuco esgrafiado. Colores y formas en la arquitectura melillense de la primera ...
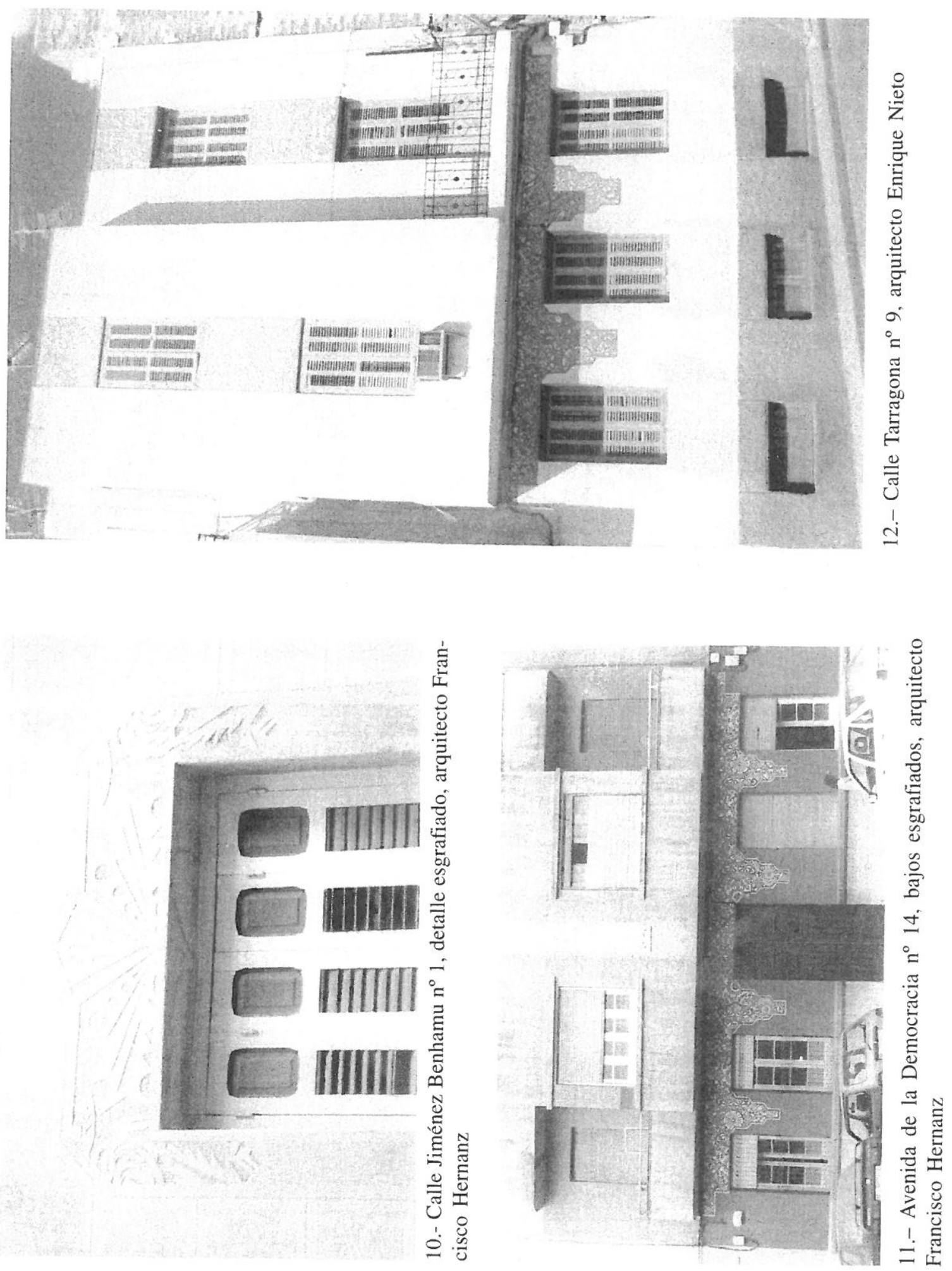


\section{Antonio Bravo Nieto}

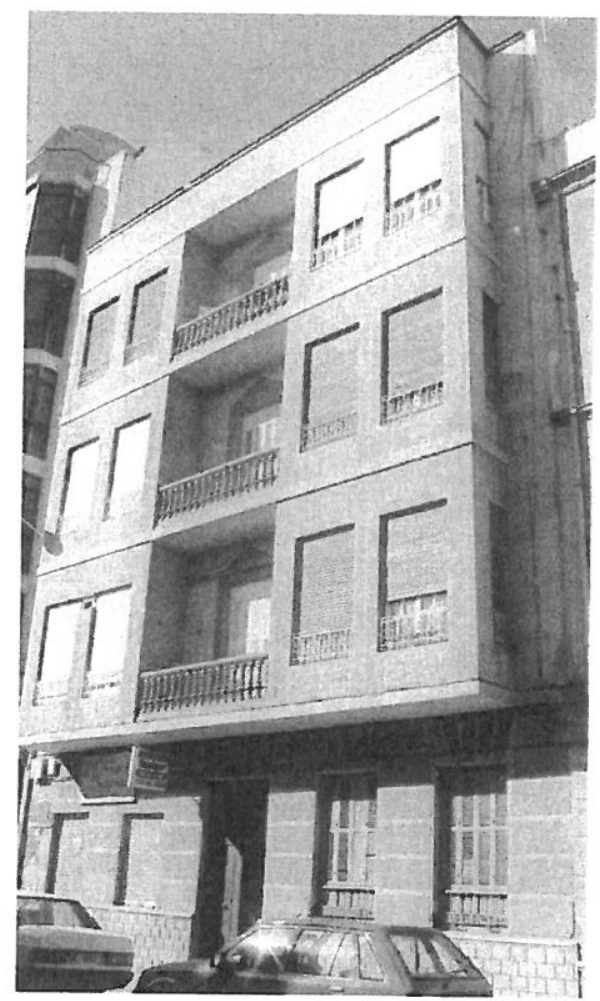

13.- Calle Duquesa de la Victoria $n^{\circ} 24$ arquitecto Enrique Nieto

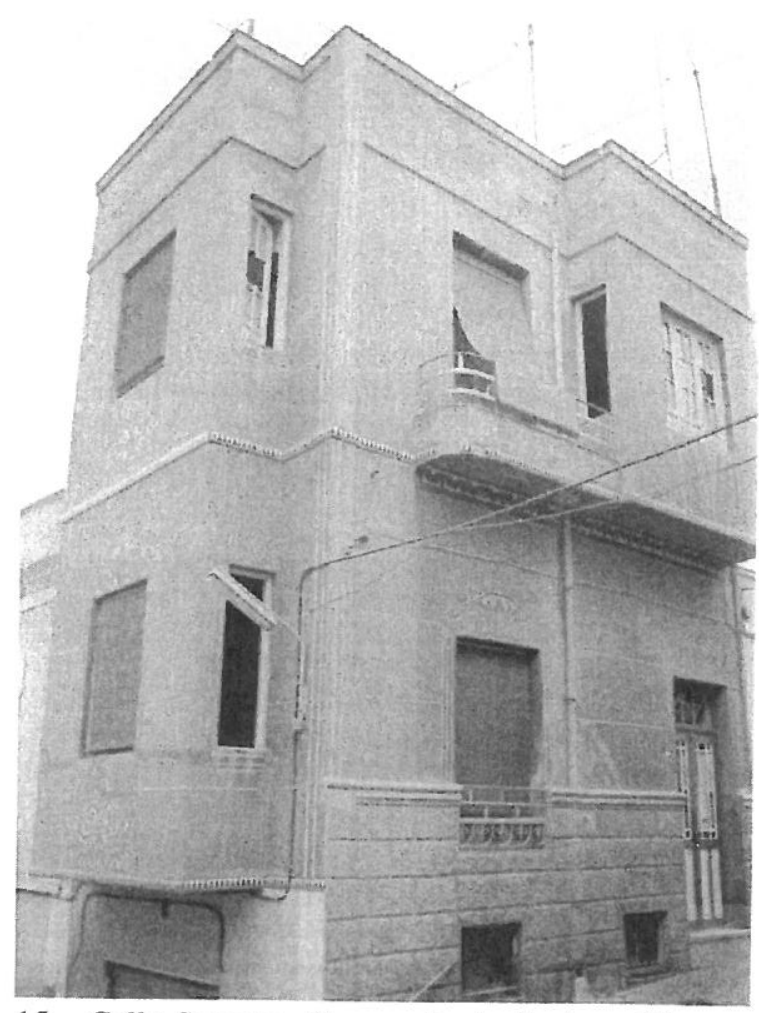

15.- Calle Sagasta $n^{\circ} 1$, arquitecto Enrique Nieto
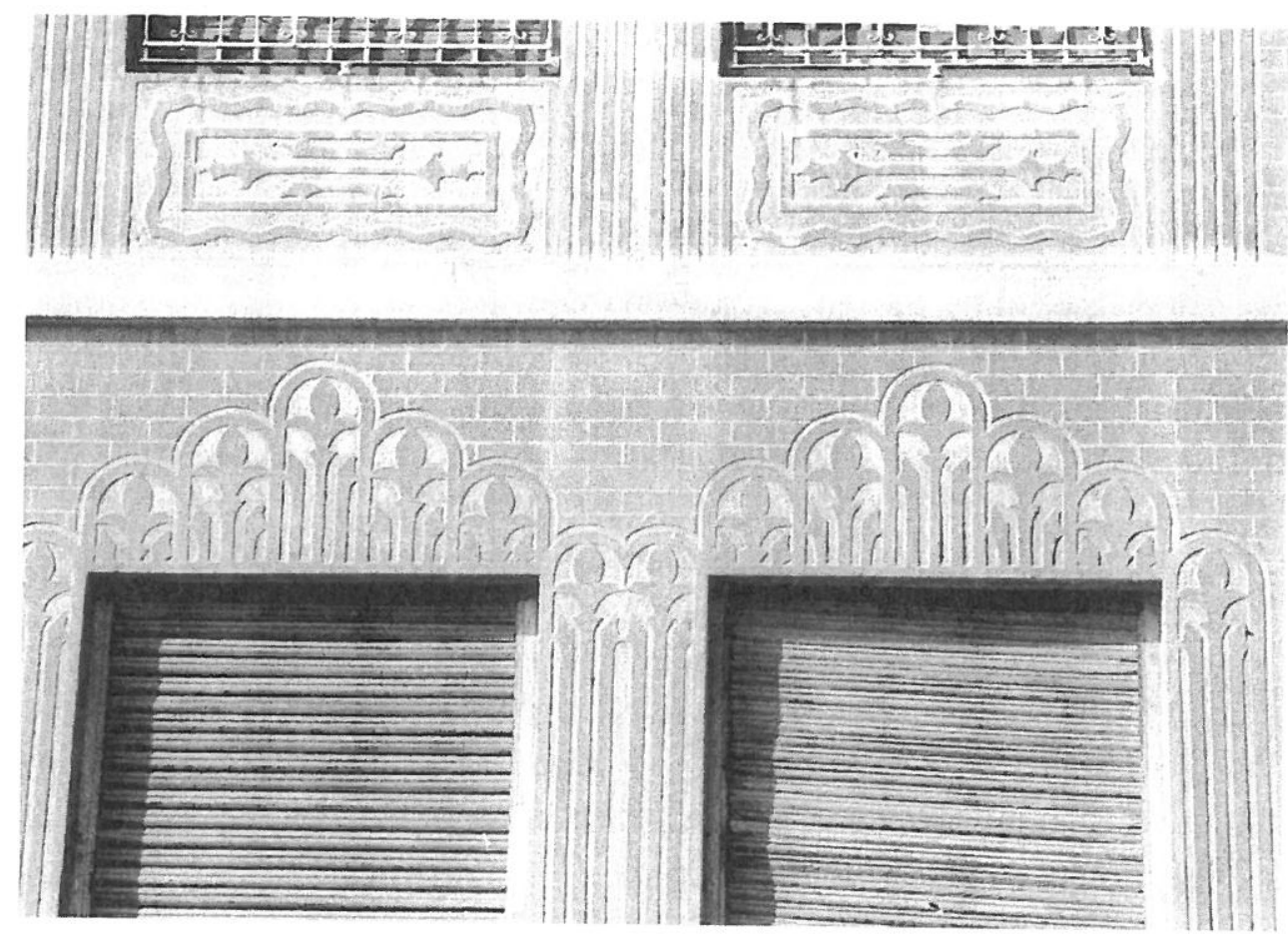

14.- Idem. Detalle de los esgrafiados 
El estuco esgrafiado. Colores y formas en la arquitectura melillense de la primera ...

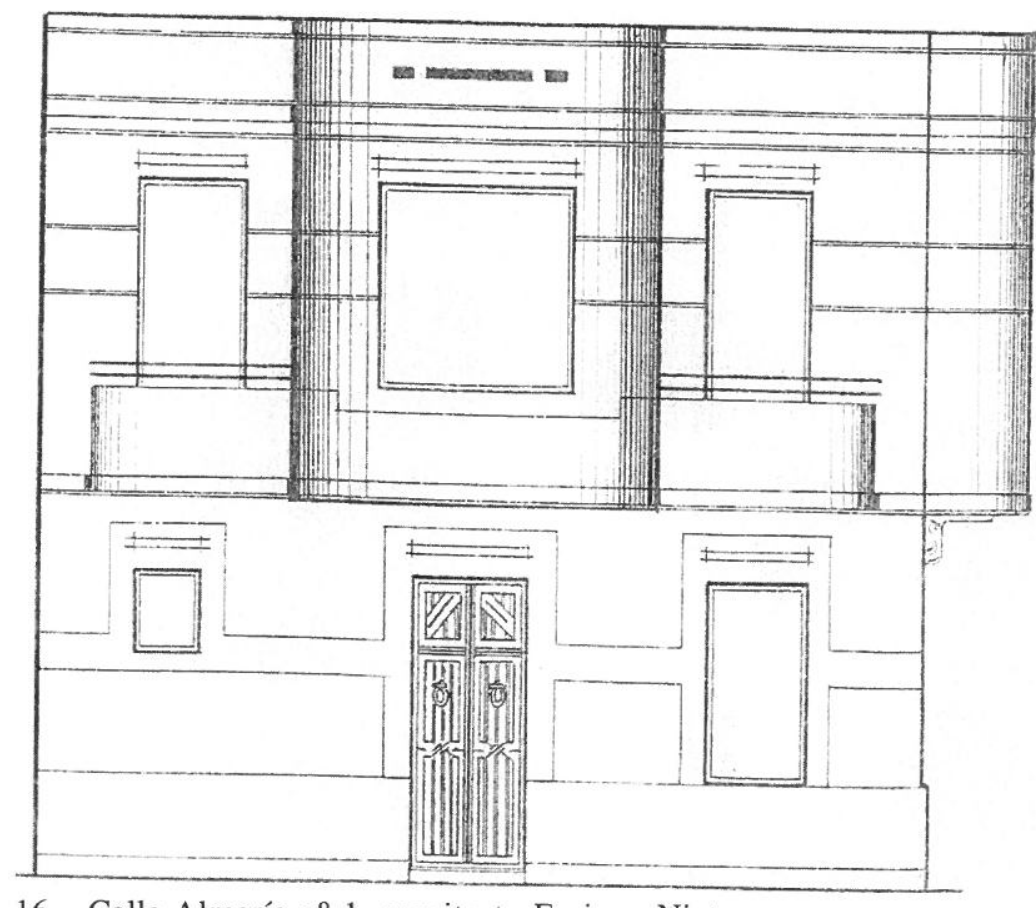

16.- Calle Almería $n^{\circ} 1$, arquitecto Enrique Nieto

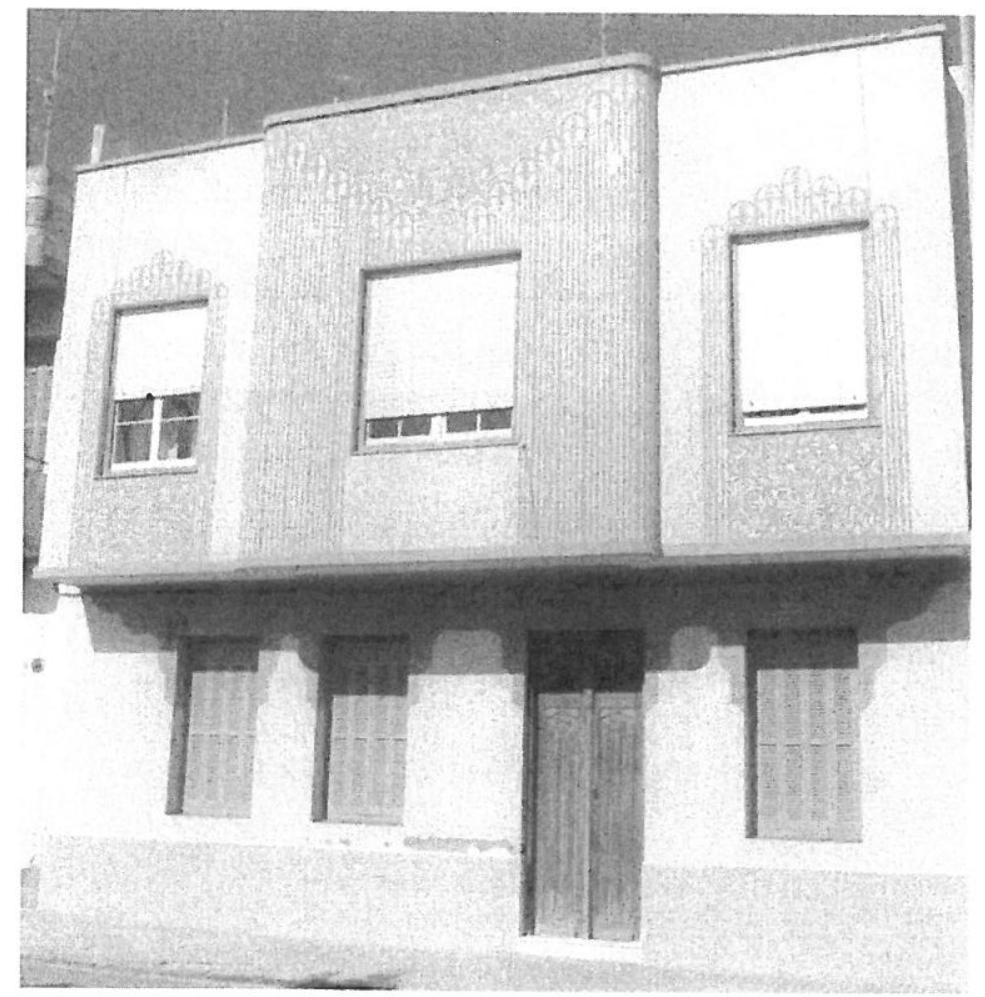

17.- Calle Aragón no 19, esgrafiados 


\section{Antonio Bravo Nieto}
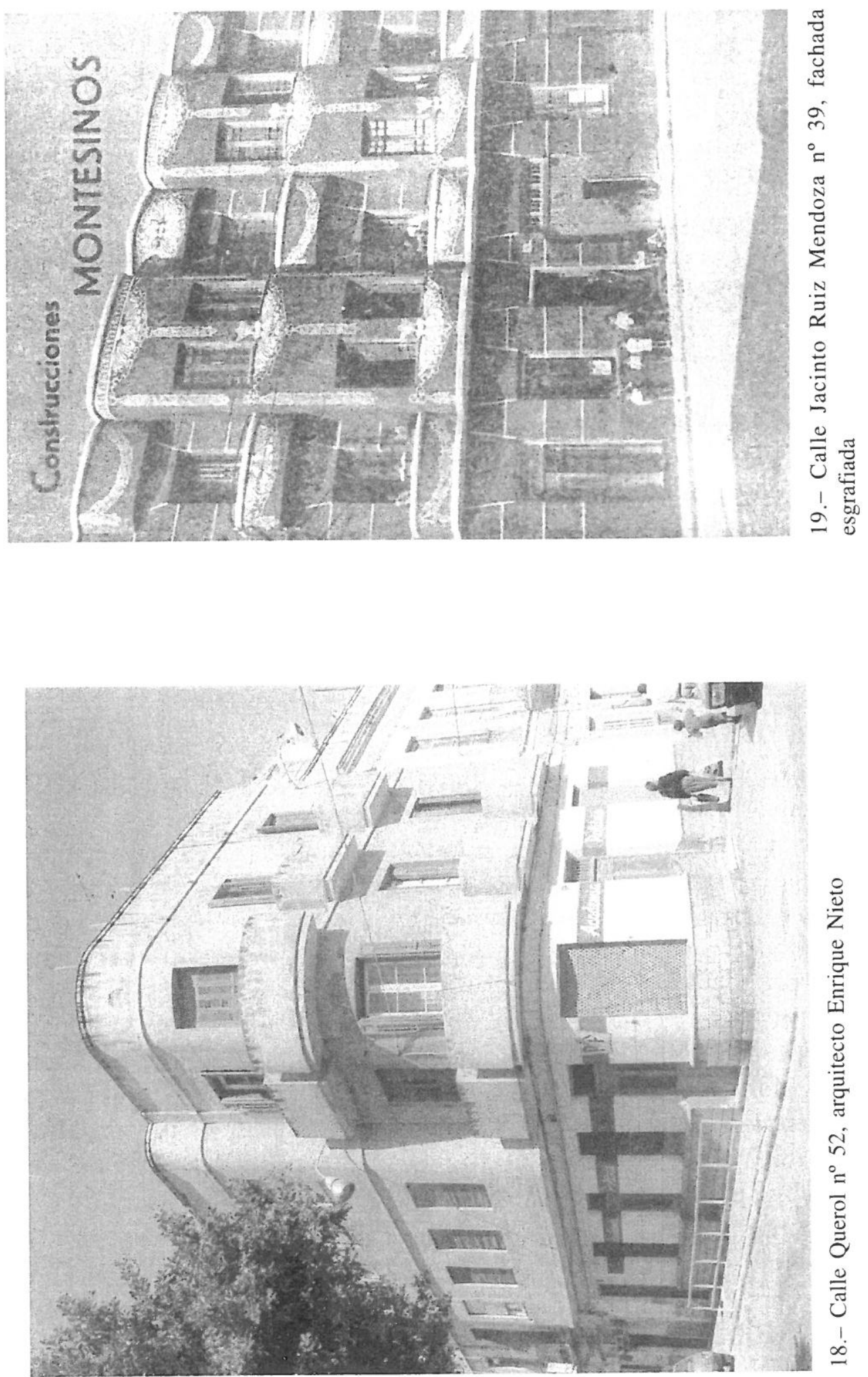